\title{
Controls on trench topography from dynamic models of subducted slabs
}

\author{
Shijie Zhong \\ Department of Geological Sciences, University of Michigan, Ann Arbor \\ Michael Gurnis \\ Seismological Laboratory, California Institute of Technology, Pasadena
}

\begin{abstract}
A finite element method with constrained elements and Lagrange multipliers is used to study tectonic faults in a viscous medium. A fault, representing the interface between overriding and subducting plates, has been incorporated into a viscous flow model of a subduction zone in which both thermal buoyancy and the buoyancy associated with the phase change from olivine to spinel are included. The fault causes stress to concentrate in its vicinity, giving rise to a weak plate margin and a mobile plate if a power law rheology is used. Surface dynamic topography with either a Newtonian or a power law rheology and with typical subduction zone parameters is characterized by a narrow and deep trench and a broadly depressed back arc basin. This suggests that oceanic trenches and back arc basins over subduction zones are dynamically compensated by viscous flow. Our models show that trench depth increases with fault dip angle, slab dip angle, slab length, and age of oceanic lithosphere just prior to subduction. The influence of fault dip angle and age of lithosphere on trench depth is greater than the influence of slab dip angle and slab length. These relationships of trench depth versus subduction zone parameters explain well the statistics of observed trench depths. For those subduction zones with oceanic lithosphere on both sides of the trench, observed trench depths have been corrected for fault and slab dip angles, based on the relationships from the dynamic models. After correction to a common set of parameters, trench depth correlates linearly with age of lithosphere prior to subduction with a slope which is close to what models having high viscosities within the transition zone and lower mantle predict. Comparison between the trench depths, corrected for fault and slab dip angles, and model trench depths suggests that the resisting tangential stress on faults in subduction zones may range from $15 \mathrm{MPa}$ to $30 \mathrm{MPa}$, depending on model details.
\end{abstract}

\section{Introduction}

Topography on the Earth's surface originates from crustal thickness variations and stresses induced by super-crustal and sub-crustal loads. The topography contrast between oceans and continents and the topographic variations in orogenic belts are generally due to crustal thickness variations. Topography due to crustal thickness variations is usually isostatically compensated and not associated with geoid anomalies at long wavelengths. The response of the Earth's surface to stress induced by buoyancy (like subducted slabs) within the mantle results in dynamic topography. Dynamic topography constrains the thermal and rheological structure of the mantle and lithosphere. Since topography is significantly affected by crustal thickness variations, it is usually difficult to distinguish dynamic topography from isostatically compensated topography. Long-wavelength dynamic topography may be deduced from residual seafloor topography [Cazenave et al., 1989; Davies and Pribac, 1993; Pribac, 1991], anomalously depressed continental hypsometry [Gurnis, 1993], and from studies of the geoid and mantle tomography [Hager et al., 1985].

Copyright 1994 by the American Geophysical Union.

Paper number $94 \mathrm{JB} 00809$.

0148-0227/94/94JB-00809\$05.00
Outer rise-trench-island arc-back arc basin topography is a diagnostic feature of subduction zone dynamics. These topographic features may be related to subduction processes in a systematic way. While island arc and back arc basin topography are influenced by volcanism and back arc spreading [Karig, 1971], trench topography probably has a dynamic origin. Outer rises are usually considered as a secondary topographic feature accompanying trenches. Trenches as dynamic topography signals may offer us important insight into subduction dynamics.

A number of characteristics of converging margins correlate with trench topography. Grellet and Dubois [1982] reported that trench depths are positively correlated with subduction rates. Hilde and Uyeda [1983] showed that trench depths increase with the age of lithosphere just prior to subduction. Hilde and Uyeda [1983] suggested that the positive correlation between trench depths and subduction rates, reported by Grellet and Dubois [1982], may be due to the positive correlation between age and subduction rates. In a statistical analysis of trench depth for subduction zones, Jarrard [1986] showed that correlation coefficients of trench depth with age of subducting lithosphere and subduction rate were 0.57 and 0.45 , respectively. Jarrard [1986] argued that the correlation with subduction rate is degraded, if the correlation between subduction rate and age prior to subduction is excluded, as suggested by Hilde and Uyeda [1983]. Moreover, intermediate 
subduction dip angles measured from the surface to $100 \mathrm{~km}$ in depth are correlated with trench depths with a correlation coefficient of 0.52 , and the overall correlation coefficient to age of subducting lithosphere and intermediate subducting dip angles is 0.77 [Jarrard, 1986]. However, dip angles of slabs at depths greater than $100 \mathrm{~km}$ and Benioff zone length are apparently not correlated with trench depths [Jarrard, 1986].

The generally deep bathymetry of back arc basins may also be related to the dynamics of slabs. Sclater [1972] and Sclater et al. [1976] pointed out that back arc basins in the western Pacific are anomalously deep for their age. Recent studies on the Philippine Sea back arc basins indicate that basement depths of those back arc basins are about $0.8 \mathrm{~km}$ deeper than those of major ocean floor of the same age [Park et al., 1990]. Residual topography, the topography corrected for crustal thickness variations, sediment loading, and lithospheric age, is anomalously deep in the back arc basin regions of the western Pacific [Pribac, 1991]. Anomalously deep back arc basin topography may be related to slabs. Systematic studies on the relationship between the characteristics of slabs and residual back arc basin topography have not yet been undertaken.

Three kinds of models have been proposed to explain the origin of outer rise, trench, island arc, and back arc basin topography of subduction zones. First, models of a thin elastic plate with a bending moment acting on trenches provide plausible explanations for outer rises and trenches [e.g., Watts and Talwani, 1974]. De Bremaecker [1977] suggested that the outer rise and trench topography could also be explained with a thin viscous plate loaded at trenches. However, these models not only fail to address how the subduction process gives rise to the force which bends plates but also cannot explain the residual back arc basin topography. Second, trench and island arc topography has been ascribed to the subduction of a plate. McKenzie [1969] showed, with a simple viscous corner flow, that subduction of a plate into the mantle induces trench-like topography over subduction zones but that the deepest part was on the overriding plate. Using a similar concept but a viscoelastic finite element method, Melosh and Raefsky [1980] found that not only trenches but also island arc topography can be explained by the pressure differences generated within the slab. The later numerical models make a direct physical connection between the origin of trenches and the subduction process.

Finally, much of the trench-island arc-back arc basin topography may be directly attributed to the negative buoyancy of slabs. The negative buoyancy not only represents the primary driving force for mantle convection but also dynamically depresses the Earth's surface in the vicinity of subduction zones. To explain Aleutian subduction zone topography, Sleep [1975] formulated a viscous flow model with a heterogeneous rheology and realistic density structure. Davies [1981] realized the importance of faults at plate boundaries, and he proposed a fractured elastic plate model in which trenches and back arc basins were partially compensated by negatively buoyant slabs. Although Davies' models can explain topography, free air, and geoid anomalies over subduction zones, the surface topography was obtained by a simple force projection rather than the solution to the momentum equation. By introducing a fault representing the plane separating the overriding from the subducting plate, Zhong and Gurnis [1992] showed, with a viscous flow model, that a trench with a depth of $3 \mathrm{~km}$ and a width of $100 \mathrm{~km}$ and a broad back arc basin with a depth of about $1 \mathrm{~km}$ can be generated with a slab of realistic thermal buoyancy and a resisting shear stress of $\sim 5 \mathrm{MPa}$ across the fault. Model trench depth is primarily determined by dip angle of a fault and age of a slab [Zhong and Gurnis, 1992], qualitatively consistent with the statistics of observed trench depths.

The magnitude of shear stress on large faults has long been a controversial subject [Kanamori, 1980]. With a frictional heating model, shear stress on the San Andreas fault is deduced from heat flow measurements to be smaller than $10 \mathrm{MPa}$ [e.g., Lachenbruch and Sass, 1988]; in subduction zones shear stress on faults ranges from 14 to $40 \mathrm{MPa}$, depending on model details [Tichelaar and Ruff, 1993]. With a simple mechanical model, Davies [1980] found that shear stress on fault planes in subduction zones had to be over $100 \mathrm{MPa}$ in order to balance internal buoyancy. The magnitude of shear stress on faults in subduction zones may be constrained by observed trench depths: a larger shear stress on a fault implies a stronger coupling between overriding plate and subducting plate, and hence slab, and for a given buoyancy force, a larger shear stress would give rise to a shallower trench.

Faults are essential to understanding lithospheric deformation in subduction zones. Mechanical models of tectonic faults have been considered in relation to earthquakes [Jungels and Frazier, 1973; Melosh and Reafsky, 1981; Lyzenga et al., 1991] and graben formation [Melosh and Williams, 1989]. Since previous studies have dealt with problems at relatively small temporal and spatial scales, the media surrounding faults are assumed to be viscoelastic. For problems at large temporal and spatial scale, such as subduction zone dynamics, a viscous rheology is more appropriate. In Zhong and Gurnis' [1992] viscous flow models of subduction zones, fault planes are treated as rigid boundaries; normal velocities on the faults vanish, and tangential velocities are discontinuous across the faults. However, rigid faults may result in discontinuous normal stresses on faults, and this requires a physically ad hoc assumption about the faults, that is, faults have to be able to support the discontinuous normal stresses without deformation. Faults may be more properly treated as deformable in the normal direction (e.g., a vertical fault of this type has been given by Barr and Houseman [1992]). For the deformable faults, both normal velocity and normal stress on faults are continuous, while the tangential velocity may be discontinuous. Despite the difference between these two types of fault models, faults are represented as a discontinuity in the tangential velocity across faults.

In this paper, we will study deformable faults using finite element methods with constrained elements and Lagrange multipliers. We will primarily focus on the flow field and surface dynamic topography induced by both a thermal buoyancy associated with subducting lithosphere and a buoyancy due to the phase change from olivine to spinel at a depth of $410 \mathrm{~km}$; the latter buoyancy was not considered by Zhong and Gurmis [1992] and may be important in determining the stress on faults [Davies, 1980]. Our computations show that for either a Newtonian or power law rheology, dynamic topography is characterized by a narrow and deep trench and a broad back arc basin, similar to those reported by Zhong and Gurnis [1992]. Stresses concentrate in the vicinity of a fault, and when a power law theology is used, the high stresses give rise to a weak plate margin and a mobile plate. Our models 
indicate that trench depth is primarily controlled by fault dip angle and age of lithosphere, consistent with the observed trend of trench depths [Jarrard, 1986]. On the basis of our models, we have corrected observed trench depths for both fault dip angle and slab dip angle for subduction zones in which the overriding plates are oceanic. After correction to a common set of parameters, the previously scattered trench depth to age of lithosphere relation becomes nearly linear. We suggest, from the corrected trench depth to age relation that the shear stress across faults may range from $15 \mathrm{MPa}$ to 30 MPa.

\section{Physical Models and Method}

We have developed a two-dimensional viscous flow model of a subduction zone with a fault using finite elements. Tectonic faults are complicated, and simplifications are necessary based on our current understanding. For the deformable fault, both normal velocity and normal stress are continuous across the fault interface, but the tangential velocity may be discontinuous across the fault plane. The flow is coupled on either side of the fault interface by an imposed resisting shear stress. A more advanced possibility would be to assume an effective coefficient of friction across the fault.

Viscous flow models have successfully been used to predict slab dip angles [Hager and $O^{\prime}$ Connell, 1978] and the depth dependence of seismicity [Vassiliou and Hager, 1988]. Our viscous flow model with a fractured lithosphere (Figure 1) includes a negative thermal buoyancy associated with subducting slabs and the negative buoyancy due to the phase change from olivine to spinel at a depth of $410 \mathrm{~km}$. The fault plane is assumed to extend down to the base of a highviscosity lithosphere. Fault dip angles, $\theta_{f}$, are implicitly the subduction dip angles within the lithosphere and are usually much smaller than slab dip angles, $\theta_{s}$, representing the Benioff zone dip angles at depths greater than $100 \mathrm{~km}$ [Jarrard, 1986]. Since trench depth strongly correlates with the $\theta_{f}$ but not with the $\theta_{s}$ [Jarrard, 1986], we independently varied these two dip angles. In all models presented here, depths of the bottoms of lithosphere, the upper mantle, and the transition zone are assumed to be $100 \mathrm{~km}, 410 \mathrm{~km}$, and $670 \mathrm{~km}$, respectively; the thickness of slabs is $100 \mathrm{~km}$; the height and length of the model box are $1500 \mathrm{~km}$ and $4500 \mathrm{~km}$, respectively; free slip boundary conditions are applied on the top and bottom boundaries, and reflecting boundary conditions are used for the two vertical boundaries. We have found that the size of model box is large enough so that the bottom and two vertical boundaries do not greatly affect the model results near the converging margin.

There are two kind of buoyancy forces within subducted lithosphere: thermal and that due to deflection of phase boundaries. Subducted lithosphere may experience three major phase changes: basalt to eclogite at a depth of 60 to $80 \mathrm{~km}$, olivine to spinel at a depth of $410 \mathrm{~km}$, and spinel to post spinel at a depth of $670 \mathrm{~km}$ [Ringwood, 1975]. Although phase change from basalt to eclogite is localized within a layer of about $6-7 \mathrm{~km}$ thick, the negative buoyancy induced by this phase change may be comparable to local thermal buoyancy, due to the large density change of this phase change. However, this negative buoyancy should be offset by the positive buoyancy of the basalt-depleted mantle underlying the oceanic crust [Oxburgh and Parmentier, 1977]. Therefore the buoyancy caused by this phase change is not
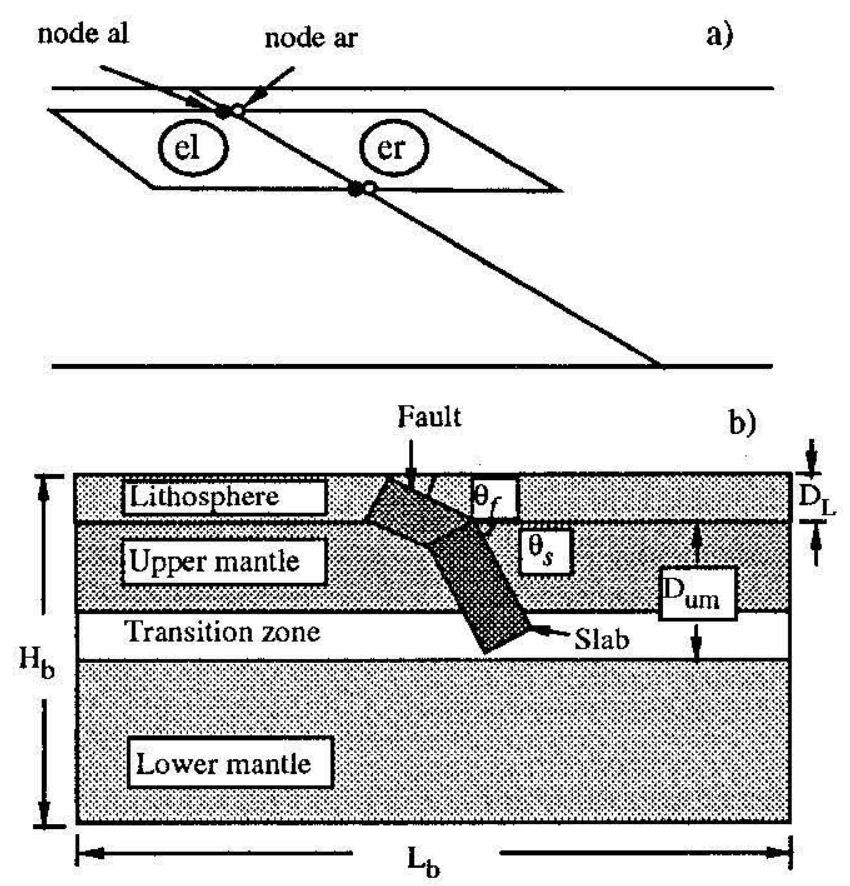

Figure 1. A viscous flow model of subduction zones with a fault. Coefficient of thermal expansion $\alpha$, gravitational acceleration $g$, density of the mantle $\rho_{0}$, and reference temperature $T_{o}$, are $2 \times 10^{-5} \mathrm{~K}^{-1}, 10 \mathrm{~m} \mathrm{~s}^{-2}, 3.3 \times 10^{3} \mathrm{~kg} \mathrm{~m}^{-3}$. and $1500 \mathrm{~K}$, respectively.

included in this study. The phase change at $670 \mathrm{~km}$ is not included because slabs in most of the cases studied here are not long enough to encounter the $670-\mathrm{km}$ phase boundary and because, as we will show, this phase change boundary is too deep to greatly affect the surface dynamic topography. Therefore only thermal buoyancy and buoyancy due to phase change from olivine to spinel at $410 \mathrm{~km}$ are taken into account. In our models, the thermal buoyancy within the slab is assumed to be uniform and is equated to the buoyancy within the oceanic plate just prior to subduction [e.g., Hager and $O^{\prime}$ Connell, 1981]. While the thermal buoyancy is relatively well constrained, the phase change buoyancy is not well known. If the thermal structure of the slab is known, then the negative buoyancy associated with the phase change from olivine to spinel may be estimated. Schubert et al. [1975] found that the olivine and spinel phase boundary was displaced upward by a maximum $115 \mathrm{~km}$ within a subducting slab; this is equivalent to a total buoyancy of about $1.6 \times 10^{13} \mathrm{~N} \mathrm{~m}^{-1}$ per unit length of trench [Davies, 1980]. Schubert et al. [1975] implicitly assumed that phase change reactions instantaneously go to completion; the negative buoyancy would be reduced if phase change kinetics are taken into account [Sung and Burns; 1976]. Since we do not solve for the thermal structure, the phase change buoyancy is simplified to a $6 \%$ density increase $\left(200 \mathrm{~kg} \mathrm{~m}^{-3}\right.$, Turcotte and Schubert [1982]) over a length $L_{p c}$ for a $100-\mathrm{km}$-thick slab at $410 \mathrm{~km}$ depth. Two different phase change buoyancy models are tested. (1) The length of the segment over which the phase change occurs is assumed to be linearly proportional to the age of a slab. The older a slab is, the colder it is, and the larger the length of the segment is. For a $100 \mathrm{~m} . \mathrm{y}$. old slab, the length of segment is assumed to be $60 \mathrm{~km}$, giving a negative buoyancy close to that of Davies [1980]. (2) Regardless of age 
of subducted lithosphere, the length of segment $L_{p c}$ is set to $60 \mathrm{~km}$.

Within the Earth's mantle the inertial forces are negligible, and the momentum and continuity equations, using the Boussinesq approximation, become

$$
\sigma_{i j, j}+f_{i}=0
$$

and

$$
u_{i, i}=0 \text {, }
$$

where $u_{i}, f_{i}$, and $\sigma_{i j}$ are the flow velocity, the body force, and the stress tensor, respectively. Throughout the paper, repeated indices denote summation. The body force and the stress tensor may be expressed in terms of a state equation and a constitutive equation as

$$
f_{i}=\rho_{o}\left[1-\alpha\left(T-T_{o}\right)\right] g \delta_{i 2},
$$

and

$$
\sigma_{i j}=-P \delta_{i j}+\mu\left(u_{i, j}+u_{j, i}\right),
$$

where $T$ is the temperature, $\rho_{o}$ and $T_{o}$ are the reference density and temperature, respectively, $g$ is the gravitational acceleration, $\alpha$ is the coefficient of thermal expansion, and $\delta_{i j}$ is kronecker delta, $P$ is the pressure, and $\mu$ is the dynamic viscosity. The equations are solved with a finite element method. In order to enforce incompressibility, a penalty formulation in which $-\lambda u_{i, i}$ is used to approximate the pressure $P$ and selective and reduced integration are used [Hughes, 1987; King et al., 1990].

Special finite element techniques are needed in order to solve the viscous flow with a fault plane. Those nodes (Figure 1) having the same coordinates but on different sides of the fault are assigned different degrees of freedom (dof), as done in interface problems in engineering [Cook, 1981]. With such dof's the flow can be decoupled or weakly coupled on either side of the fault, depending on the constraints and prescribed shear stress. Constraints on the fault may be realized with constrained element techniques for those elements adjacent to the fault. For a system like ours with few constraints, a Lagrange multiplier method is very effective [Cook, 1981].

The constraints for realizing the faults can be written for deformable faults as

$$
u_{n}^{a r}-u_{n}^{a l}=0
$$

and

$$
\sigma_{n}^{e r}-\sigma_{n}^{e l}=0,
$$

where $u_{n}^{a r}$ and $u_{n}^{a l}$ are normal velocities for nodes $a r$ and $a l$ on the fault which have the same coordinates but are on different sides of the fault (i.e., nodes $a r$ and al are on the right and left sides of the fault, respectively; e.g., Figure $1 \mathrm{a}) ; \sigma_{n}$ is a normal stress on the fault; element indices $e r$ and $e l$ are for those elements that have one side on the fault plane (e.g., Figure 1a). The normal stress can be expressed as

$$
\sigma_{n}=\sin ^{2}\left(\theta_{f}\right) \sigma_{x x}+\cos ^{2}\left(\theta_{f}\right) \sigma_{y y}+\sin \left(2 \theta_{f}\right) \sigma_{x y} .
$$

The constraints (5) and (6) can be rewritten, respectively, as

$$
u_{x}^{a r} \sin \left(\theta_{f}\right)+u_{y}^{a r} \cos \left(\theta_{f}\right)-u_{x}^{a l} \sin \left(\theta_{f}\right)-u_{y}^{a l} \cos \left(\theta_{f}\right)=0,
$$

and

$$
\sum_{a=1}^{n_{e n}}\left(f_{e r}^{1 a} u_{x}^{a}+f_{e r}^{2 a} u_{y}^{a}\right)-\sum_{a=1}^{n_{e n}}\left(f_{e l}^{l a} u_{x}^{a}+f_{e l}^{2 a} u_{y}^{a}\right)=0,
$$

where $n_{e n}$ is the number of nodes per element and equal to four for the quadrilateral elements used here; $f_{e}^{1 a}$ and $f_{e}^{2 a}$ are defined for element $e(e=e r$ or $e l)$ as

$$
\begin{aligned}
& f_{e}^{1 a}=\left[\lambda+2 \mu \sin ^{2}\left(\theta_{f}\right)\right] N_{a, x}+\mu \sin \left(2 \theta_{f}\right) N_{a, y}, \\
& f_{e}^{2 a}=\left[\lambda+2 \mu \cos ^{2}\left(\theta_{f}\right)\right] N_{a, y}+\mu \sin \left(2 \theta_{f}\right) N_{a, x},
\end{aligned}
$$

where $N_{a, x}$ and $N_{a, y}$ are the derivatives of shape functions of node $a$ with respect to $x$ and $y$ coordinates, respectively. Equations (6) to (9) are essentially a projection of elemental to nodal stresses. Such a projection is necessary, because stress is defined at reduced gaussian quadrature points [Hughes, 1987] rather than directly on the nodes of elements in our finite element solution of incompressible viscous flow.

Any constraint, like these made in equations (8) and (9), can be written in the form of a matrix equation:

$$
[C]\{D\}=\{Q\},
$$

where $\{D\}$ is a vector containing velocity. To solve for the flow with a constraint, equation (12), is equivalent to minimizing a potential [Cook, 1981]

$$
\Pi=\frac{1}{2}\{D\}^{t}[K]\{D\}-\{D\}^{t}\{R\}+\{\alpha\}([C]\{D\}-\{Q\}),
$$

where the first two terms represent the regular potential for the fluid flow and the third term is from the constraint, equation (12); entries in $\{\alpha\}$ are called Lagrange multipliers; $[K]$ and $\{R\}$ are the ordinary stiffness matrix and force vector, respectively. Besides body and boundary forces, $\{R\}$ also includes contributions from the resisting shear stress on the faults, through which force flow is coupled between two sides of the faults. Minimizing $\Pi$ with respect to both $\{D\}$ and $\{\alpha\}$ yields a matrix equation

$$
\left[\begin{array}{cc}
K & C^{t} \\
C & 0
\end{array}\right]\left\{\begin{array}{l}
D \\
\alpha
\end{array}\right\}=\left\{\begin{array}{l}
R \\
Q
\end{array}\right\} .
$$

Solving equation (14) gives the flow incorporating the constraint, equation (12). Equation (14) must be carefully solved since it is not positive definite. For a system with a few constrained elements, the Lagrange multiplier method is very efficient and easily implemented.

Both Newtonian and non-Newtonian theologies have been used in this study. For Newtonian models, viscosities of the lithosphere, the upper mantle, transition zone, and the lower mantle are assumed to be $1.5 \times 10^{22}, 3 \times 10^{20}, 6.0 \times 10^{21}, 3 \times$ $10^{22} \mathrm{~Pa} \cdot \mathrm{s}$, respectively (Figure 2 ); viscosity of slab within the upper mantle and the transition zone are $4.5 \times 10^{21}$ and $6.0 \times$ $10^{21} \mathrm{~Pa} \cdot \mathrm{s}$, respectively. This radial viscosity structure for the lithosphere and mantle is generally consistent with that derived from long-wavelength geoid studies [Hager, 1990]. Because of the temperature dependent rheology of mantle materials, slabs may have a higher viscosity than the ambient mantle. Non-Newtonian rheology, or strain rate dependent viscosity, is essential to making the plate mobile by weakening plate margins [Christensen, 1983; King and Hager, 
1990]. Following King [1991], for non-Newtonian flow, the strain rate is related to stress as

$$
\dot{\varepsilon}=A\left(\frac{\sigma}{\sigma_{o}}\right)^{n},
$$

where $\dot{\varepsilon}$ and $\sigma$ are the second invariant of the strain rate and stress tensors, respectively; $\sigma_{o}$ is a reference stress; $n$ is the exponent and is equal to 3 in this study; $A$ represents the temperature, pressure, and compositional dependence of viscosity. The effective viscosity is defined as

$$
\eta_{\text {eff }}=\frac{\sigma}{2 \dot{\varepsilon}}=\frac{\sigma_{o}}{2 A^{\frac{1}{n}} \dot{\varepsilon}^{\left(1-\frac{1}{n}\right)}}
$$

The non-Newtonian rheology causes the equation of motion, equation (1), to be nonlinear; the nonlinear equation is solved iteratively [King, 1991]. The lithosphere, the upper mantle, the transition zone, and the lower mantle have different $A$ (equation (15)); $A$ is chosen such that the final average effective viscosity for a region is close to that used in Newtonian models.

The surface has zero normal velocity as a boundary condition, but normal stress induced by flow can be nonzero. Dynamic topography is determined from surface normal stress by assuming that the surface will deform with the normal stress such that no net traction acts on the surface; dynamic topography is

$$
h=\frac{\sigma_{y y}}{\Delta \rho g},
$$

where $\Delta \rho$ is the density contrast between lithosphere and the media (e.g., water) overriding lithosphere. A consistent boundary flux method [Zhong et al., 1993] is used to compute normal stresses on the surface after obtaining flow velocity from equation (14). Because the normal stress is discontinuous at the intersection of the fault with the surface, the normal stress is assigned by the average value of the two adjacent surface nodes.

In general, the normal velocity on the model fault is nonzero, and this implies that the fault may migrate horizontally and change its dip angle, depending on the distribution of buoyancy and geometry of the fault plane and slab. The nonstationary fault is consistent with observations of trench migration which presumably means that faults migrate. In this study, we do not study the time dependence of subducted slabs and faults, which requires a coupled solution to the energy equation. Here we attempt to investigate the flow and topographic structure caused by a given buoyancy and fault geometry. We assume that the buoyancy structure and fault geometry have been maintained for such a long time that the calculated dynamic topography is established. It is the buoyancy forces that drive both mantle flow and motion of the fault, and fault geometry cannot change significantly unless the buoyancy distribution changes significantly. This suggests that the timescale for motion of the fault cannot be larger than the timescale for the redistribution of the buoyancy. The characteristic time for the redistribution of the buoyancy associated with slabs may be $1 \mathrm{~m} . \mathrm{y}$. or larger, and the 0.1 to $0.01 \mathrm{~m} . \mathrm{y}$. is the time it takes dynamic topography to reach equilibrium at a wavelength of about 100 to $10^{3} \mathrm{~km}$ given a viscosity of $10^{21} \mathrm{~Pa} \cdot \mathrm{s}$ [Richards and Hager, 1984].
The average effective viscosity of the lithosphere within trenches is about $10^{21} \mathrm{~Pa} \cdot \mathrm{s}$ in our non-Newtonian models; therefore the assumption that the model trench and back arc topography reaches equilibrium is valid.

\section{Results and Discussion}

Our computations for a wide range of model parameters, including Newtonian and power law rheologies, consistently show that when a deformable fault is introduced into a viscous flow model of subduction zones, dynamic topography over a slab is characterized by a narrow and deep trench and a broad back arc basin. A fault causes stress to concentrate in its vicinity, which, when a power law rheology is used, gives rise to a weak plate margin and the plate becomes mobile. Trench depth varies with fault dip angles $\theta_{f}$, slab dip angles $\theta_{s}$, slab age $\tau_{s}$, slab length $L_{s}$, and the resisting shear stress on the fault. However, for a given resisting shear stress, fault dip angle and slab age are the two most important parameters influencing trench depth. The observed trench depths, after being corrected for slab dip and fault dip based on our models, show a clear linear correlation to slab age and with a slope which is close to what our models predict. From the corrected trench depth relationship to slab age, we suggest that shear stress on convergent boundaries ranges from $15 \mathrm{MPa}$ to 30 MPa.

In what follows we will first show general characteristics of dynamic topography and flows from our fault models with different rheologies; second, check our model resolution and discuss the possible effects of lithosphere flexure and volcanic arcs on dynamic topography; third, systematically determine the relation between trench depth and fault dip, slab dip, age and length of slab, and resisting shear stress on faults; and, finally, interpret observed trench depths from the perspective of model results.

\section{Dynamic Topography and Flow: Effects of Faults}

Two cases with a deformable fault are computed for Newtonian and non-Newtonian rheology, respectively; the other parameters are zero resisting shear stress, a fault dip $\theta_{f}$. of $30^{\circ}$, a slab dip $\theta_{s}$, of $60^{\circ}$, a length of $700 \mathrm{~km}$, and an age of $80 \mathrm{~m} . \mathrm{y}$. For the non-Newtonian case, the preexponents of the power law rheology (i.e., $A$ in equation (15)) for the lithosphere, the upper mantle, the transition zone, the lower mantle, and the slab are chosen such that the horizontally averaged effective viscosity profile is similar to that used in Newtonian models (Figure 2). For both cases, dynamic topography is characterized by a narrow and deep trench-like and a broad depression or back arc basin-like topography (Figure 3a). For the non-Newtonian case, the trench is about $100 \mathrm{~km}$ wide and $5.0 \mathrm{~km}$ deep; the maximum depression of 3.6 $\mathrm{km}$ behind the trench is about $150 \mathrm{~km}$ from the trench; at a distance of about $300 \mathrm{~km}$ behind the trench, the magnitude of depression decreases rapidly to about $0.6 \mathrm{~km}$, and from there the depression of the back arc region gradually decreases to zero over about $1700 \mathrm{~km}$ (Figure 3a). We also observe an outer rise topography of about $0.3 \mathrm{~km}$ for the non-Newtonian case (Figure 3a). For the Newtonian case, the outer rise topography becomes less evident, and the trench depth and the maximum depression behind the trench tend to be larger than those from the non-Newtonian models (Figure 3a). 


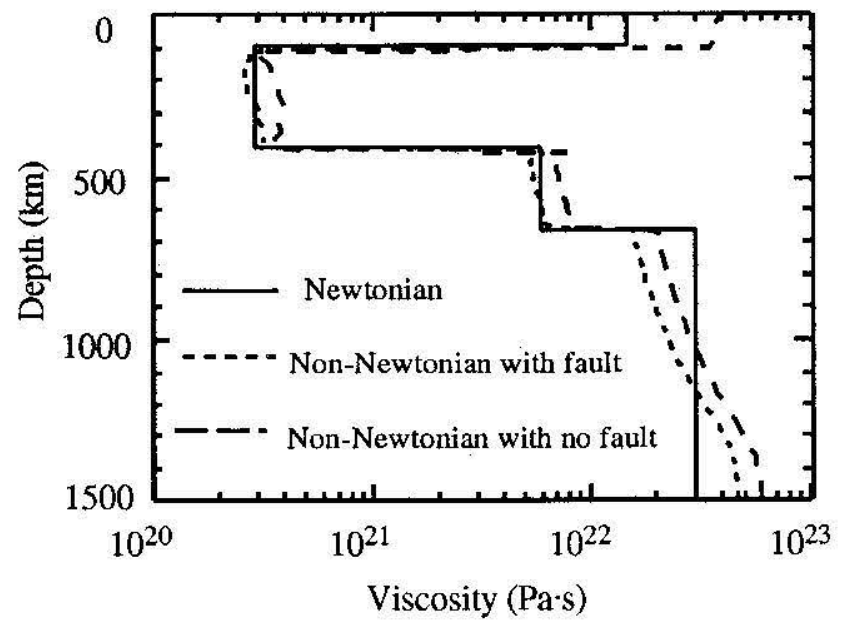

Figure 2. Viscosity profiles for Newtonian and nonNewtonian deformable fault models and a non-Newtonian model with no fault.
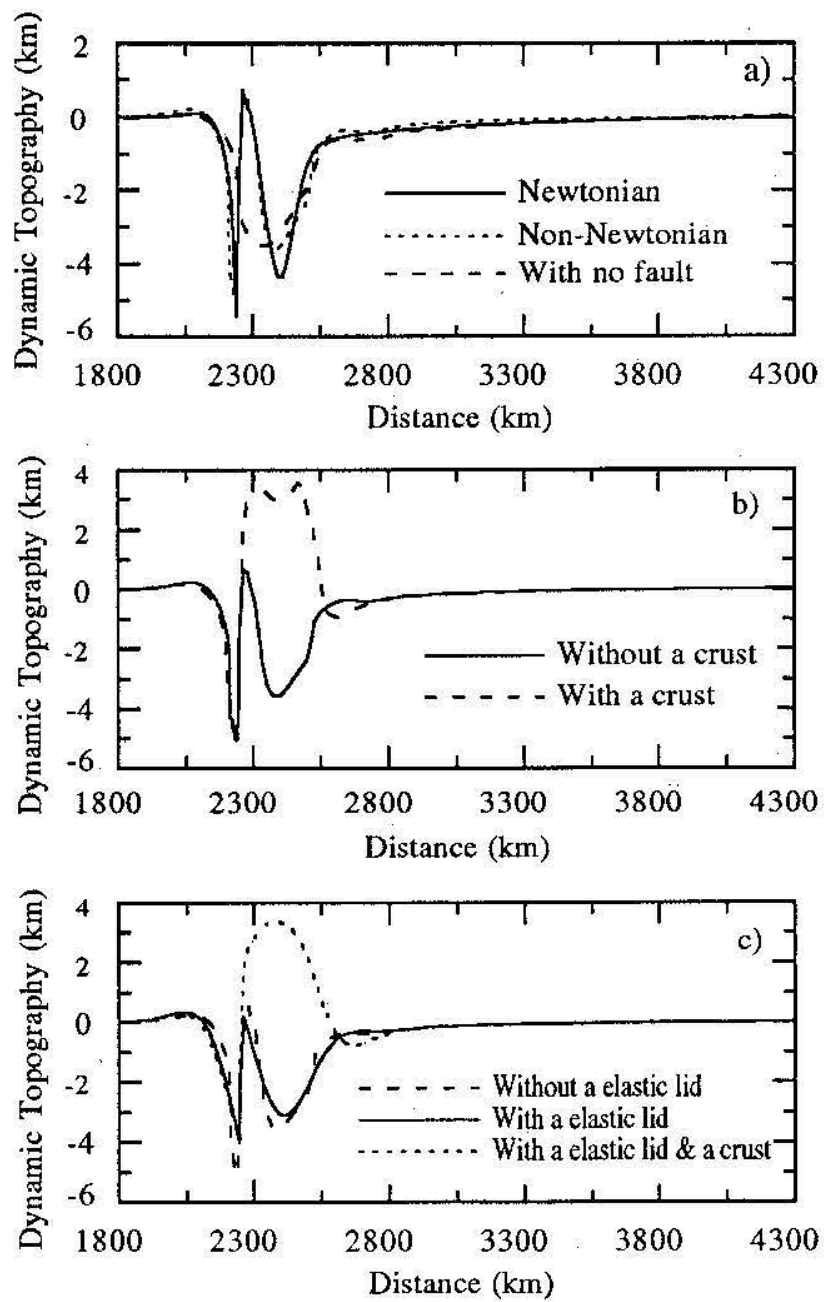

Figure 3. Dynamic topography profiles (a) for fault models with Newtonian rheology and non-Newtonian rheology, and a non-Newtonian model with no fault, (b) for models with and without a crust, and (c) for models with and without a thin elastic plate.

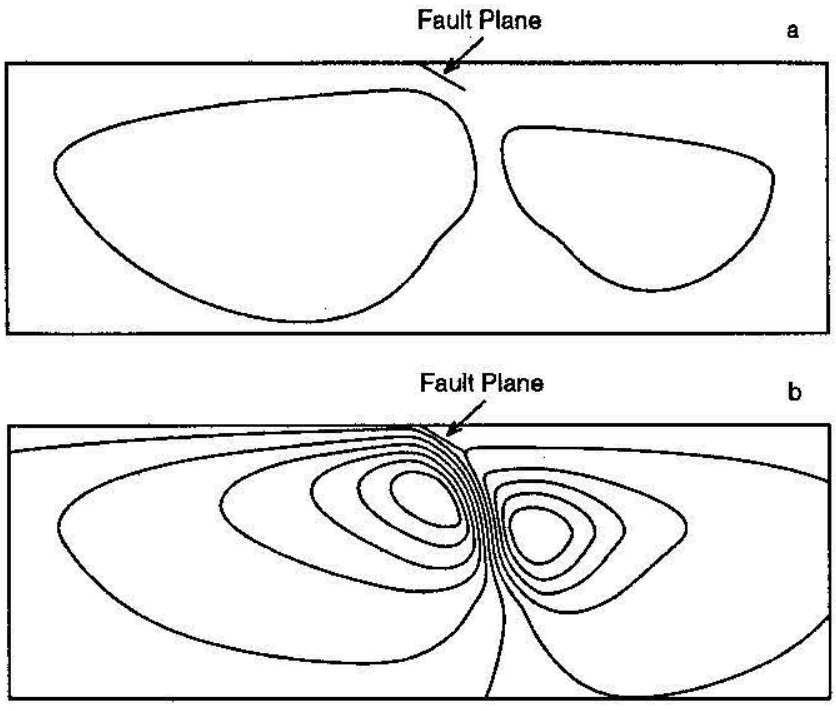

c

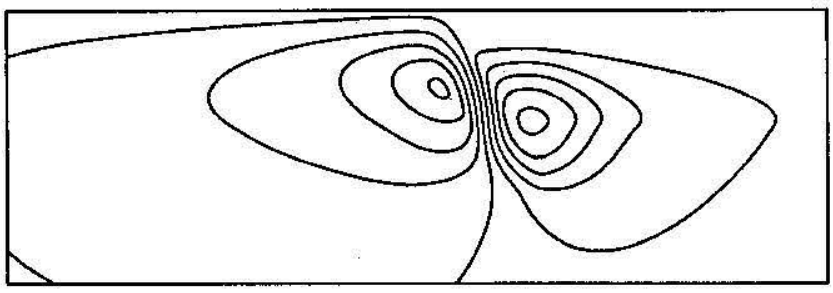

Figure 4. Streamlines with the same contour values for (a) Newtonian and (b) non-Newtonian deformable fault models and (c) non-Newtonian model with no fault. The maximum and minimum values of stream function for Figures $4 \mathrm{a}, 4 \mathrm{~b}$, and $4 \mathrm{c}$ are $6.0 \times 10^{-5} \mathrm{~m}^{2} \mathrm{~s}^{-1}$ and $-5.6 \times 10^{-5} \mathrm{~m}^{2} \mathrm{~s}^{-1}, 5.3 \times 10^{-4} \mathrm{~m}^{2} \mathrm{~s}^{-1}$ and $-5.2 \times 10^{-4} \mathrm{~m}^{2} \mathrm{~s}^{-1}$, and $5.3 \times 10^{-4} \mathrm{~m}^{2} \mathrm{~s}^{-1}$ and $-6.4 \times 10^{-4} \mathrm{~m}^{2}$ $\mathrm{s}^{-1}$, respectively.

The dynamic topography from the cases with deformable faults (Figure 3a) is similar to that from a rigid fault model [Zhong and Gurnis, 1992], although the magnitude of the maximum depression behind the trench from the deformable faults is substantially larger. The rigid fault of Zhong and Gurnis [1992] may support much of the topography that would be otherwise transmitted onto the surface and cause a greater depression behind the trench if normal deformation on faults is allowed. Nevertheless, the similarities between dynamic topography from these two different kinds of fault models suggest that the discontinuity in tangential velocity on faults, a common feature of these two faults, is essential to producing trench topography.

The flows differ significantly between the Newtonian and non-Newtonian cases. For the Newtonian case, the high viscosity of the slab causes the flow to lock up (Figure 4a); the maximum velocities of lithosphere just prior to subduction and of the slab within the mantle are $1.9 \mathrm{~cm} / \mathrm{yr}$ and $3.8 \mathrm{~cm} / \mathrm{yr}$, respectively. If the slab viscosity is decreased to the values of its ambient mantle, then the maximum velocity of slab increases to about $7.6 \mathrm{~cm} / \mathrm{yr}$, while the lithosphere remains immobile with a maximum velocity of $1.0 \mathrm{~cm} / \mathrm{yr}$. The lithosphere velocity prior to subduction cannot be significantly less than slab velocity; otherwise, the slab would detach from the lithosphere [Sleep, 1975]. When the 
non-Newtonian rheology is used, the subducting lithosphere has a much larger velocity than the overriding lithosphere does, indicating asymmetric subduction; the subduction velocity is close to the slab velocity (Figure $4 \mathrm{~b}$ plotted with the same contour values as those in Figure 4a). The maximum velocity of the lithosphere just prior to subduction is 13.6 $\mathrm{cm} / \mathrm{yr}$; the slab velocity is about $22.0 \mathrm{~cm} / \mathrm{yr}$.

The mobile plate results from the weakening of plate margins due to the stress dependent viscosity [e.g., Christensen, 1983]. When a fault is present, stress tends to concentrate near the fault, especially within the subducting plate, which is evident from the surface dynamic topography (e.g., Figure 3a); the high stress near the fault weakens plate margins and gives rise to a mobile subducting plate (Figure 4b). For comparison, a case, which does not include any fault, but otherwise is identical to the non-Newtonian fault case, is presented (viscosity profile in Figure 2, topography in Figure $3 \mathrm{a}$, and flow field in Figure $4 \mathrm{c}$ ). It is evident that stresses near the fault within the subducting plate become larger when a fault is present (Figure 3a for topography or surface normal stress), which weakens the subducting plate more efficiently. As a result, the lithosphere viscosity becomes smaller compared to the no fault case (Figure 2), and subduction velocity and asymmetry of subduction are enhanced (Figures $4 b$ and $4 c)$.

Asymmetric subduction and a comparable velocity between subducting lithosphere and slab [Sleep, 1975] are two important characteristics of subduction zones. We have found that both characteristics can be achieved in the models shown in Figures $4 a, 4 b$, and $4 c$ with a high-viscosity slab and lithosphere, although the magnitudes of velocities for the Newtonian model are much smaller. When the slab viscosity is assumed to be the same as ambient mantle, velocity of the subducting lithosphere becomes comparable to velocity of overriding lithosphere but much smaller than slab velocity. This suggests that both the asymmetric subduction and a comparable velocity between subducting lithosphere and slab are probably due to the coupling between the high-viscosity slab and lithosphere.

For either Newtonian or non-Newtonian cases, when the resisting shear stress on the fault is zero, the tangential velocity is discontinuous across the fault, and the tangential velocity on the subducting lithosphere side of the fault is much larger than that on the overriding lithosphere side. For the non-Newtonian case (Figure $4 \mathrm{~b}$ ), the average tangential velocities on the subducting lithosphere side and the overriding lithosphere side are $16.7 \mathrm{~cm} / \mathrm{yr}$ and $2.8 \mathrm{~cm} / \mathrm{yr}$, respectively. The difference between these two tangential velocities becomes small when the resisting shear stress or the frictional force on the fault is increased.

Another important difference between Newtonian and nonNewtonian models is the nature of normal stress near faults. Since model trench topography (i.e., the normal stress) changes greatly near faults (Figure $3 \mathrm{a}$ ), detailed studies including resolution study on the topography near faults are necessary. For the cases presented in Figure $3 \mathrm{a}$, a mesh referred to as mesh 1 is refined near the fault with $10 \mathrm{~km}$ horizontal spacing between elements in the vicinity of the fault. When the mesh is doubled near the fault (referred to as mesh 2), for both Newtonian and non-Newtonian cases with faults (Figure $3 a)$, the maximum changes in flow velocity due to the changes in meshes are found to be only about $0.1 \%$. However, dynamic topographies from the Newtonian and the non-Newtonian
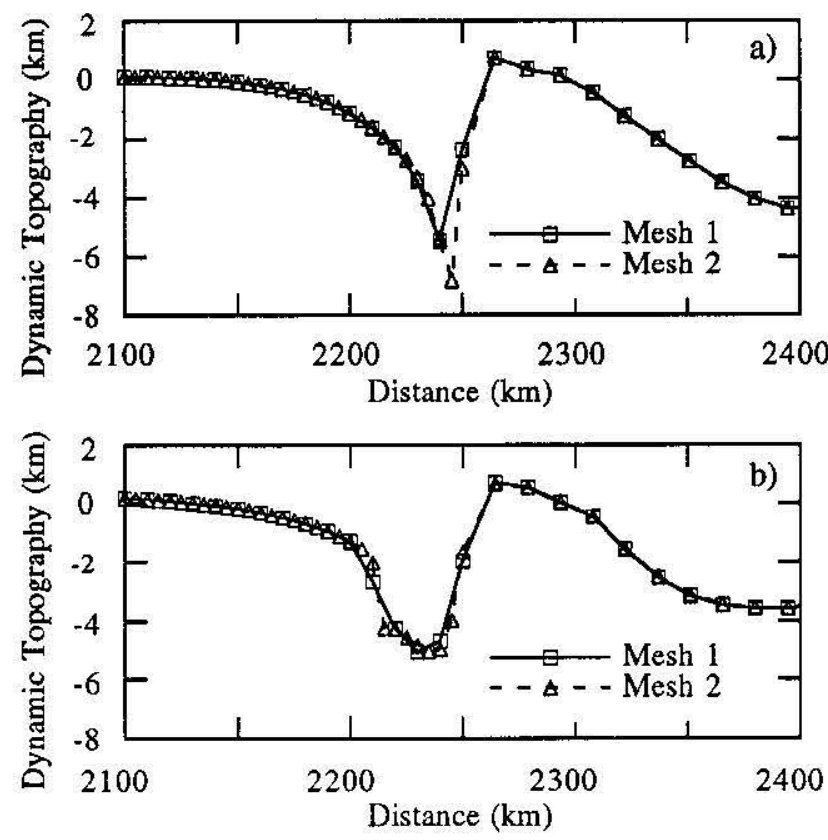

Figure 5. Resolution studies of dynamic topography for (a) Newtonian and (b) non-Newtonian rheology.

cases show different responses to the changes in meshes. For the Newtonian case, while the doubled mesh (mesh 2 in Figure 5a) yields almost the same topography as mesh 1 does (mesh 1 in Figure 5a) at most nodes, the topography at the node on the fault and the node next to the fault node on the left side of the fault are deeper than those from mesh 1 (Figure 5a). The deepest trench depth for the Newtonian models increases as the mesh is refined; this is probably due to the singularity in normal stress induced by the faults. For the non-Newtonian rheology, the singularity apparently vanishes, and both mesh 1 and mesh 2 produce almost identical dynamic topography (Figure 5b). The stress-dependent rheology is crucial not only for producing mobile plates but also for yielding physically reasonable normal stresses. For this sakc, we will use nonNewtonian rheology in all the following models.

The morphology of the model outer rise, trench, and back arc depression ( $300 \mathrm{~km}$ behind the trench) from the nonNewtonian case (Figure $3 a$ ) are close to those for observed outer rises, trenches, and back arc basins, assuming that island arc topography is due to isostatic compensation. The model outer rise, same as the trench, is a purely viscous phenomenon. The elasticity of lithosphere is not necessary to be invoked to explain the outer rise [De Bremaecker, 1977]. The model back arc depression which in general is about 0.3 $\mathrm{km}$ over a broad back arc region may be slightly smaller than observed back arc basin depth. Other processes which are not considered in our models including back arc spreading may also contribute to the observed back arc depression. It should be pointed out that the maximum depression of $150 \mathrm{~km}$ behind the model trench (Figure $3 a$ ) is usually where topographically bigh volcanic island arcs are located. As we mentioned earlier, island arc topography is primarily due to the isostatic compensation of volcanic rocks [Sleep, 1975]. Island arcs primarily consist of basalts; the lower-density basalts could be locally compensated and give rise to topographic highs. In order to illustrate this process, a case which only differs from the non-Newtonian case in having a crust of volcanic rocks 
has been computed. The density of the crust is taken to be 300 $\mathrm{kg} \mathrm{m}^{-3}$ smaller than that of ordinary lithosphere. The crust is located right above the fault; the width of the crust is about $300 \mathrm{~km}$ on the surface, and its width tapers to about $70 \mathrm{~km}$ at $45 \mathrm{~km}$ depth. The density and shape of the crust are very close to those given by Sleep [1975]. The resulting dynamic topography (Figure $3 b$ ) explains well the observed subduction zone topography including trench, island arc, and back arc basin. More importantly, the model trench topography is insensitive to the inclusion of the crust, and the trench depth decreases by only about $0.25 \mathrm{~km}$, compared with the case without the crust (Figure $3 \mathrm{~b}$ ). Therefore in all the subsequent models of trench depth, no crust of volcanic rocks is included.

The dynamic topography determined from purely viscous stresses may also be affected by the elastic rigidity of the lithosphere. This effect is investigated by a thin elastic plate with a end free [Zhong and Gurnis, 1992]. The elastic lithosphere thickness increases with lithospheric age, but this thickness becomes constant at about $25 \mathrm{~km}$ when lithospheric age is greater than 35 m.y. [Watts et al., 1980]. This corresponds to a flexural rigidity of $1.4 \times 10^{23} \mathrm{~N} \mathrm{~m}$ assuming a Young's modulus of $1.0 \times 10^{11} \mathrm{~N} \mathrm{~m}^{-2}$ and a Poisson's ratio of 0.25 [Watts et al., 1980]. Since the ages of lithosphere in our models of trench depth are all greater than $40 \mathrm{~m}$.y., we study only the effect of a thin elastic plate with a flexural rigidity of $1.4 \times 10^{23} \mathrm{~N} \mathrm{~m}$. After loading the thin elastic plate by the normal stress from the non-Newtonian case (Figure 3a), the general characteristics of the topography remain unchanged (Figure 3c), but the trench depth decreases by about $22 \%$ (i.e., $1.1 \mathrm{~km}$ ) and the island arc topography is slightly decreased and smoothed (Figure $3 \mathrm{c}$ ). It should be pointed out that for a given flexural rigidity and distribution of normal stress acting on the elastic plate, the deformation (i.e., topography) of the plate is linear to the magnitude of normal stress [Hetenyi, 1946].

Relationships of Trench Depth to $\theta_{s}, \theta_{f}, L_{s}$, and $\tau_{s}$

We now systematically study the effects of the four primary parameters of subduction zones, i.e., dip angles of faults, $\boldsymbol{\theta}_{f}$ dip angles of slabs, $\theta_{s}$, length of slabs, $L_{s}$, and age of lithosphere prior to subduction, $\tau_{s}$, on trench depth. When computing these covariations, we fix three of the four parameters, and then compute trench depth as a function of the fourth parameter. Each set of subduction zone parameters represents a distinct model of subduction zones; an evolutionary relation is not assumed between any two subduction zones.

Our computations show that the trench depth in general increases with slab dip angle (Figure 6a), fault dip angle (Figure 6b), slab length (Figure 6c) and age of lithosphere (Figure 6d). For these models of trench depth, resisting shear stresses on faults are either zero or $10 \mathrm{MPa}$, and the effects of elasticity are not included. From these relationships of trench depth to $\theta_{s}, \theta_{f}, L_{s}$, and $\tau_{s}$, we can observe that trench depth does not uniformly vary with these four parameters; fault dip angles $\theta_{f}$, age of lithosphere $\tau_{s}$, and slab length $L_{s}$ have more important effects on trench depth than do slab dip angles $\theta_{s}$. For zero resisting shear stress cases, trench depth increases by about $3.9 \mathrm{~km}, 3.6 \mathrm{~km}$ and $2.7 \mathrm{~km}$, respectively, as $\theta_{f}, \tau_{s}$, and $L_{s}$ are varied from $20^{\circ}$ to $45^{\circ}$ (Figure $6 \mathrm{~b}$ ), from 40 m.y. to 160
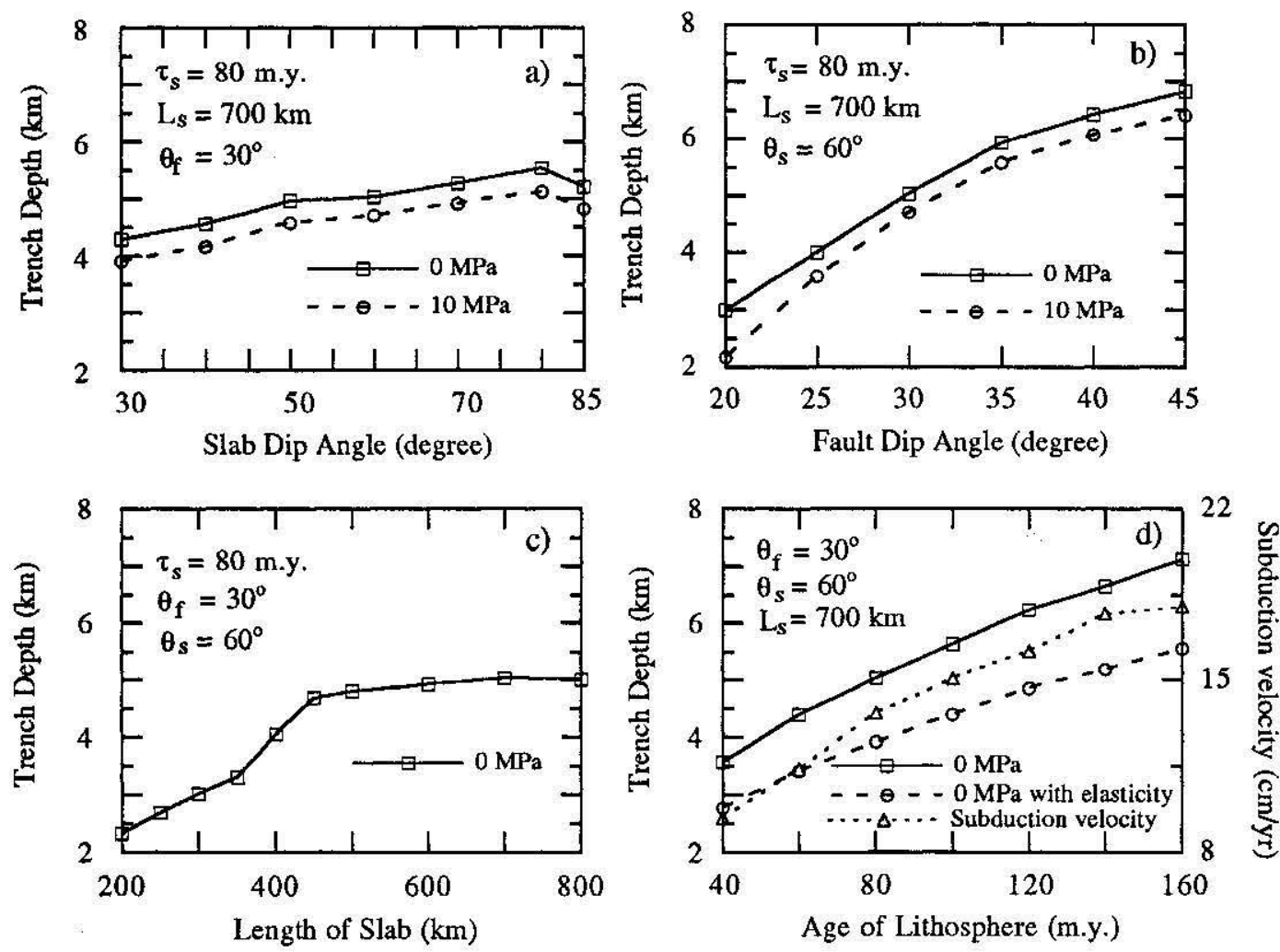

Figure 6. Dependencies of trench depth on (a) slab dip angle, (b) fault dip angle, (c) length of slab, and (d) age of lithosphere. Trench depth with a thin elastic lid and subduction velocity relations to age of lithosphere are shown (Figure 6d). The other three parameters and the resisting shear stress for each case are also shown. 
m.y. (Pigure 6d), and from $200 \mathrm{~km}$ to $800 \mathrm{~km}$ (Figure $6 \mathrm{c}$ ); trench depth increases by only about $1.0 \mathrm{~km}$ when $\theta_{s}$ changes from $30^{\circ}$ to $85^{\circ}$ (Figure $6 \mathrm{a}$ ). Trench depth increases rapidly with slab length when slab length increases up to about 400 $\mathrm{km}$, but then changes only slightly as slab length increases beyond $450 \mathrm{~km}$ (Figure $6 \mathrm{c}$ ). The rapid change in trench depth when $L_{s}$ is about $400 \mathrm{~km}$ results from the rapidly increasing buoyancy which is induced by the phase change at $410 \mathrm{~km}$. Further increases of slab length from $450 \mathrm{~km}$ do not greatly change trench depth. This suggests that trench depth is not sensitive to far-field buoyancy; this justifies our exclusion of the buoyancy associated with the phase change from spinel to pervoskite at $670 \mathrm{~km}$. Trench depth decreases as the resisting shear stress on faults increases to $10 \mathrm{MPa}$, but the slopes change only slightly (Figures $6 \mathrm{a}$ and $6 \mathrm{~b}$ ). When a thin elastic plate with a flexural rigidity of $1.4 \times 10^{23} \mathrm{~N} \mathrm{~m}$ is loaded by the normal stresses resulting from the above models, trench depths are reduced by approximately $22 \%$, but so are the slopes of the trench depth to the four subduction zone parameters (e.g., Figure 6d). The reductions in trench depth are similar because the distributions of the normal stress acting on the elastic plates are all quite similar, and as discussed earlier, the deformation of the plates is linear to the magnitude of normal stress. The inclusion of a thin elastic lid does not change the conclusion of which parameters influence trench depth most.

These relationships allow us to qualitatively explain observed statistics of trench depth [Jarrard, 1986]. Parameters for subduction zones are generally within the ranges shown in Figure 6. Age of lithosphere $\tau_{s}$ varies from about $15 \mathrm{~m}$.y. in the southwest Mexican subduction zone to about $155 \mathrm{~m} . \mathrm{y}$. in Marianas subduction zone [Jarrard, 1986]; $\theta_{f}$ changes from about $15^{\circ}$ in Chile subduction zone to $44^{\circ}$ in New Hebrides subduction zone [Jarrard, 1986]; dip angle of slabs varies between $30^{\circ}$ and $85^{\circ}$; and $L_{s}$, if we equate it with the length of Benioff zone, varies from 100 to over $10^{3} \mathrm{~km}$. Among the four subduction zone parameters, slab length may be the most uncertain. Seismic studies suggest that the length of Benioff zones poorly represents the length of the slabs. For example, the Benioff zone in the Aleutians extends to only $200 \mathrm{~km}$ depth, but a detectable high seismic velocity anomaly may exist as deep as $400 \mathrm{~km}$ [Zhao et al., 1993]. If the length of thermal slabs is indeed large enough that slabs experience the $410-\mathrm{km}$ phase change, our model results (Figure 6) suggest that trench depth has a high correlation with $\tau_{s}$ and $\theta_{f}$ and little or no correlation with $L_{s}$ and $\theta_{s}$, consistent with the observed statistics of trench depth [Jarrard, 1986]. The correlation between trench depth and subduction velocity [Grellet and Dubois, 1982; Hilde and Uyeda, 1983] is also a direct consequence of the physics in our models. Clearly, an older lithosphere means a larger amount of negative buoyancy (assuming that other parameters are identical) and therefore results in a larger subduction velocity (Figure $6 \mathrm{~d}$ ).

It should be pointed out that in our non-Newtonian (stress dependent) calculations, the effective viscosity structure may be different from case to case, because any change in those four subduction parameters will cause change in stress, i.e., the effective viscosity. The preexponents, $A$, in equation (15) for lithosphere, the lower mantle, and slab are larger than those for the upper mantle and transition zone in order to obtain higher viscosities within lithosphere, the lower mantle, and the slab. For models with slabs of a given age, a set of preexponents, $A$, has been determined such that the horizontally averaged viscosities are similar to those used in Newtonian models (e.g., Figure 2). Such determined $A$ have been used for models with slabs of that given age. This is partly justified since $A$ represents the temperature dependence of viscosity and should be dependent on slab age. However, we have found that the use of a common set of preexponents for different slab age causes only a slight change in the topography; the relative difference in trench depth between 40 and $160 \mathrm{~m}$.y. old slabs changes by only $0.15 \mathrm{~km}$. However, using a common set of $A$ results in subduction velocities that are much too large for old slabs compared to young slabs: old slabs have more buoyancy and result in smaller effective viscosities.

\section{Dependency of Observed Trench Depth on Age}

Although the dependence of observed trench depth on age of lithosphere is scattered, a positive correlation is evident. Hilde and Uyeda [1983] suggested that trenches with anomalous depths were associated with subduction of marginal basin lithosphere, but Jarrard [1986] argued that no such relationship could be identified from his statistical analyses of trench depth. Since we have obtained theoretical relationships between trench depth and four important parameters of subduction zones and since resisting shear stress affects only the absolute magnitude of trench depth and not the slopes (Figure 6), we may use these relationships to correct the observed trench depth for fault dip, slab dip, and slab length to a common set of parameters. If shear stresses on fault planes do not differ significantly among subduction zones, we should expect the corrected trench depth to be linearly proportional to age. We will first present the corrected trench depths derived from those relationships excluding an elastic lid, and then show results including one.

Ten subduction zones in which $\theta_{f}, \tau_{s}, L_{\mathrm{BZ}}\left(L_{\mathrm{BZ}}\right.$ here is Benioff zone length), and $\theta_{s}$ are known have been chosen from Jarrard [1986] (Table 1). We have avoided continental overriding plates to avoid possible complications by rheological and density structure. The trench depth to age relation for these subduction zones is not clearly linear (Figure 7a). The Marianas trench, with a $155 \mathrm{~m} . \mathrm{y}$. lithosphere, is 4.95 $\mathrm{km}$ deep (Figure 7a). The Solomon trench is nearly as deep, $4.42 \mathrm{~km}$, but the subducting lithosphere is only $50 \mathrm{~m} . \mathrm{y}$. old. For the corrections, we have chosen a standard model: $\theta_{f}=$ $30^{\circ}, \theta_{s}=60^{\circ}$, and $L_{s}=700 \mathrm{~km}$.

Correction for $\theta_{s}$ has only a slight effect on the trench depth to age relation, because trench depth is not very sensitive to $\theta_{s}$ (Figure $6 \mathrm{a}$ ). The largest change accompanies the correction for Marianas trench: trench depth decreases by $0.4 \mathrm{~km}$ after correcting $\theta_{s}$ from $81^{\circ}$ to $60^{\circ}$. The further correction for $\theta_{f}$ dramatically changes the trench depth to age relation (Figure $7 \mathrm{~b}$ ). Because of large $\theta_{f}$ in Solomon, South Sandwich, New Britain and New Hebrides subduction zones, these trenches decrease in depth substantially after correction, and the Marianas and Lesser Antilles trenches increase in depth because of their relatively small $\theta_{f}$. The resulting trench depth to age relation (Figure $7 b$ ) displays a much better linear trend than does the observed (Figure 7a). However, further correction for $L_{\mathrm{BZ}}$ results in a significant increase in trench depth for young subduction zones but almost no change for old subduction zones (Figure $7 \mathrm{c}$ ). This is because Benioff zone length for young subducting lithosphere is much shorter than that for old subducting lithosphere and the $700 \mathrm{~km}$ standard. 
Table 1. Subduction Zone Parameters [after Jarrard, 1986]

\begin{tabular}{lcccccc}
\hline Symbol & Segment Name & $\begin{array}{c}\theta_{f}, \\
\text { deg }\end{array}$ & $\begin{array}{c}\theta_{s}, \\
\text { deg }\end{array}$ & $\begin{array}{c}\tau_{s}, \\
\text { m.y. }\end{array}$ & $\begin{array}{c}L_{\mathrm{BZ},}, \\
\mathrm{km}\end{array}$ & $\begin{array}{c}\text { Trench Depth, } \\
\mathrm{km}\end{array}$ \\
\hline Ker & Kermadec & 30 & 71 & 113 & 600 & 4.49 \\
Ton & Tonga & 28 & 57 & 120 & 930 & 5.24 \\
Nhb & New Hebrides & 44 & 73 & 52 & 340 & 2.56 \\
Sol & Solomon & 42 & 84 & 50 & 600 & 4.42 \\
Nbr & New Britain & 35 & 58 & 50 & 380 & 3.73 \\
Mar & Marianas & 24 & 81 & 155 & 770 & 4.95 \\
Izu & Izu-Bonin & 28 & 65 & 146 & 830 & 3.54 \\
Alu & Central Aleutians & 31 & 64 & 54 & 370 & 1.64 \\
Ant & Lesser Antilles & 22 & 51 & 68 & 380 & 1.80 \\
Sco & South Sandwich & 38 & 67 & 49 & 330 & 3.81 \\
\hline
\end{tabular}

Note that $\theta_{f}, \theta_{s}$ and trench depth are DipI, DipD, and differential trench depth, $\Delta d$, respectively, in Jarrard [1986] notation. $L_{\mathrm{BZ}}$ are computed from the vertical and horizontal slab extent given by Jarrard [1986]

Linear regressions for corrected trench depths show that the slopes of regression lines are $32 \mathrm{~m} \mathrm{m.y.} .^{-1}$ and $11 \mathrm{~m} \mathrm{m.y.}{ }^{-1}$ and that the coefficients of correlation are 0.83 for trench depths corrected for $\theta_{s}$ and $\theta_{f}$ (Figure 7b) but only 0.42 for trench depths corrected for $\theta_{s}, \theta_{f}$ and $L_{\mathrm{BZ}}$ (Figure $7 \mathrm{c}$ ). Trench depth to age relations for the standard model with zero shear stress and $30 \mathrm{MPa}$ shear stress on the fault have a slope of $30 \mathrm{~m} \mathrm{~m} . \mathrm{y}^{-1}$ and $33 \mathrm{~m} \mathrm{~m} . \mathrm{y}^{-1}$, respectively (Figure $8 \mathrm{~b}$ ), close to that with correction for $\theta_{s}$ and $\theta_{f}$. The correction for Benioff zone length not only significanily degrades the correlation between trench depth and age but it also leads to a much smaller slope compared to the dynamic model. This suggests that Benioff zone length may not represent the length of thermal slabs, consistent with travel time residual sphere analysis [e.g., Creager and Jordan, 1984] and seismic tomography [e.g., Zhao et al., 1993].

To use those trench depth relations to $\theta_{s}, \theta_{f}$, and $L_{\mathrm{BZ}}$ with a thin elastic lid included to do the corrections does not significantly affect our results. This is because corrections involve only relative variations of trench depth and the elastic lid uniformly reduces the relative depths by about $22 \%$ for the rigidity used. The slope of the linear regression for the trench
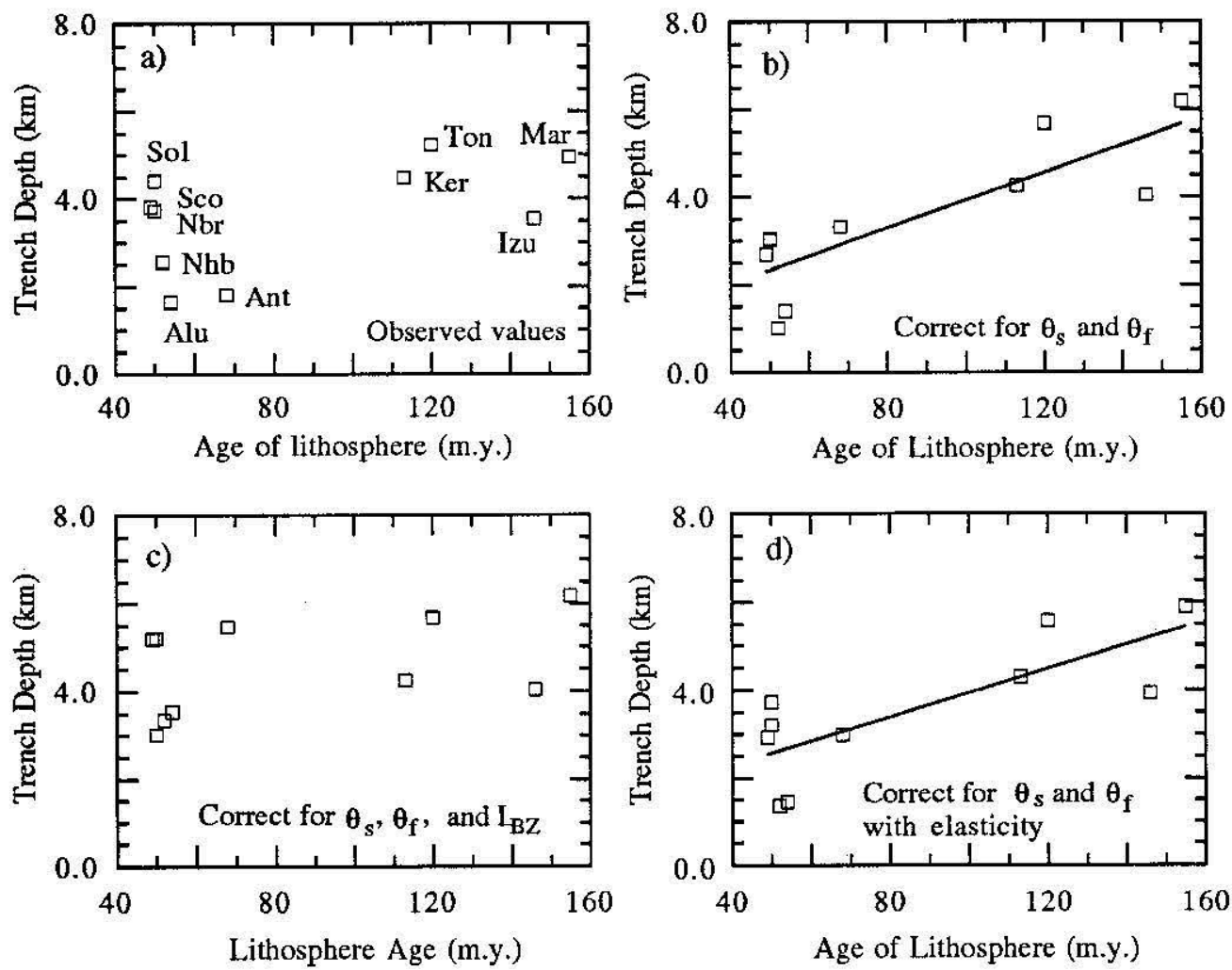

Figure 7. (a) Observed trench depths and (b) those after correction for slab and fault dip angles, and (c) after correction for slab and fault dip angles and slab length. (d) Trench depths corrected for slab and fault dip angles with a thin elastic lid. The solid lines in Figures $7 \mathrm{~b}$ and $7 \mathrm{~d}$ are the linear regression lines. See Table 1 for abbreviations of segments. 

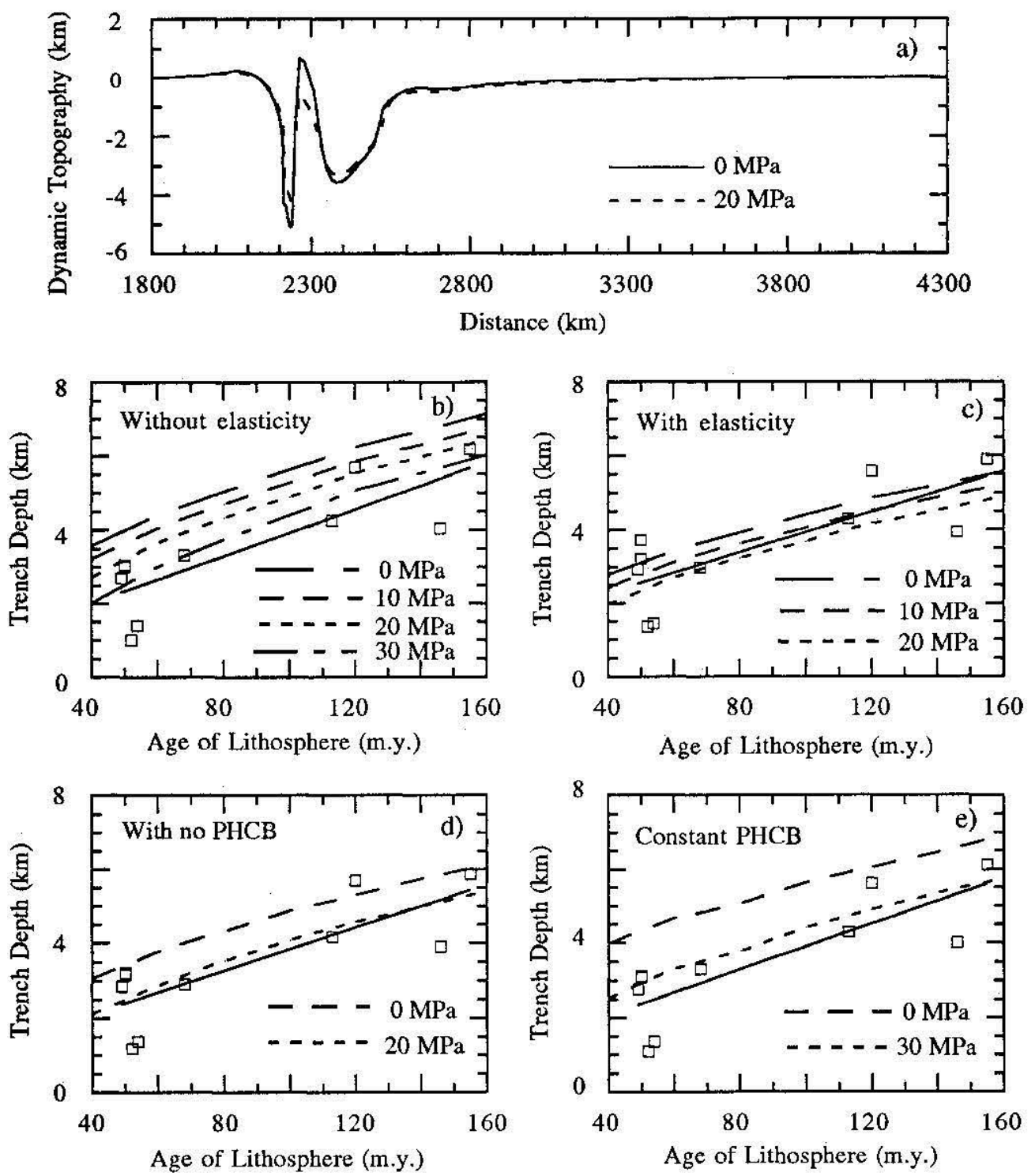

Figure 8. (a) Effects of resisting shear stress across faults on dynamic topography. Trench depth relations to age of lithosphere for the standard models with different resisting shear stresses on faults (b) excluding and (c) including a thin elastic lid. Effects of (d) no phase change buoyancy and (e) constant phase change buoyancy on the estimate of resisting shear stress on faults are also shown. PHCB stands for phase change buoyancy. The solid lines are the linear regression lines for corrected trench depths for each cases.

depths corrected for $\theta_{s}$ and $\theta_{f}$ decreases to $27 \mathrm{~m} \mathrm{m.y.}{ }^{-1}$ and the coefficient of correlation also slightly reduces to 0.78 (Figure $7 \mathrm{~d})$. This slope is also close to those for the standard model when the effects of elasticity are included, which are about 23 and $24 \mathrm{~m} \mathrm{~m} . \mathrm{m}^{-1}$ for zero and $20 \mathrm{MPa}$ shear stresses, respectively (Figure $8 \mathrm{c}$ ).

\section{Implications to Resisting Shear Stress on Convergent Plate Boundaries}

Increasing resisting shear stress on the fault plane (i.e., increasing the coupling between subducting and overriding plates) will cause trench depth to decrease [Zhong and Gurnis, 1992]. This suggests that we may estimate the magnitude of resisting shear stress by comparing model trench depth with observed trench depth. Although the coupling between subducting and overriding plates (i.e., the resisting shear stress) may differ among subduction zones in terms of maximum sizes of earthquakes [Uyeda and Kanamori, 1979], we have not attempted to study the variability of the resisting shear stress between different subduction zones; but rather, we have assumed a constant shear stress for all subduction zones. The estimated resisting shear stress from models excluding the elasticity will be presented first and then the effects of elasticity and different buoyancy distribution will be discussed.

For the standard model (i.e., $\theta_{f}=30^{\circ}, \theta_{s}=60^{\circ}$, and $L_{s}=700$ $\mathrm{km}$ ), a 20-MPa resisting shear stress, applied uniformly on the upper $50 \mathrm{~km}$ of the fault in depth, causes trench depth to decrease by $0.7 \mathrm{~km}$ compared to that with a zero resisting shear stress (Figure 8a). The shear stress results in less depression of the back arc region (Figure 8a). The tangential velocities averaged over the segment of fault on which the 20MPa shear stress is applied are $11.0 \mathrm{~cm} / \mathrm{yr}$ on the subducting lithosphere side and $6.0 \mathrm{~cm} / \mathrm{yr}$ on the overriding lithosphere 
side, in contrast to $16.7 \mathrm{~cm} / \mathrm{yr}$ and $2.8 \mathrm{~cm} / \mathrm{yr}$ for the case with zero shear stress. Trench depth to age relations are computed for the standard model with different shear stresses on the fault. Although trench depth changes with the shear stress, the slopes of trench depth versus age for different shear stresses are nearly identical (Figure $8 b$ ). Plotted on Figure $8 \mathrm{~b}$ are the trench depths corrected for $\theta_{f}$ and $\theta_{s}$ and their linear regression (i.e., Figure 7b); the effects of elasticity were not considered in these corrected trench depths. We observe that the $30-\mathrm{MPa}$ shear stress line is close to the linear regression line for the corrected trench depth. This leads us to conclude that shear stress on faults in subduction zones may be about $30 \mathrm{MPa}$. When the effects of elasticity are included, comparison between the corrected trench depths and those from standard models suggests a $15-\mathrm{MPa}$ resisting shear stress (Figure $8 \mathrm{c}$ ).

It should be pointed out that a few corrected trench depths are either far below the $30-\mathrm{MPa}$ line in Figure $8 \mathrm{~b}$ or above the $0-\mathrm{MPa}$ line in Figure 8c. However, we find that the resisting shear stress cannot exceed $40 \mathrm{MPa}$; otherwise, for subduction zones younger than $60 \mathrm{~m} . y$., the tangential velocity on the fault on the overriding lithosphere side becomes larger than that on the subducting lithosphere side, which contradicts the original sign of the resisting shear stress. This implies that our models cannot-explain some corrected trench depths. Two possibilities may resolve this discrepancy: (1) some raw trench depths include significant fraction of nondynamic topography including sediments, as discussed by Hilde and Uyeda [1983], making trenches appear shallower, and (2) uncertainties in the measured fault and slab dips and uncertainties in model parameters including negative buoyancy and mantle viscosity, as discussed below.

The magnitude of the resisting shear stress determined from our models depends on total buoyancy within the slab and viscosity structure. A smaller phase change buoyancy or a higher mantle viscosity would yield a smaller resisting shear stress. Phase change kinetics which were excluded in previous calculations of phase change buoyancy tend to reduce the negative buoyancy [Sung and Burns, 1976], and thus the estimated resisting shear stress. However, we find that even after the phase change buoyancy is excluded, a $20-\mathrm{MPa}$ resisting shear stress is still needed in order to match the trench depths corrected for fault and slab dips without taking into account elasticity (Figure $8 \mathrm{~d}$ ). We have assumed a linear relationship between the amount of phase change buoyancy and age of lithosphere in computing trench depth to age relation (e.g., Figure 8 b). To assume a constant phase change buoyancy for different ages of subducting slabs causes the slopes of trench depth to age relations to decrease by about 5 $\mathrm{m} \mathrm{m} . \mathrm{y}^{-1}$ (Figure $8 \mathrm{e}$ without the elasticity). This does not greatly change our estimate of resisting shear stress (Figure $8 \mathrm{e})$. When calculating those corrected trench depths in Figures $8 \mathrm{~d}$ and $8 \mathrm{e}$, trench depth to fault dip and slab dip relations for models with corresponding phase change buoyancy structures were used, respectively. A higher-viscosity mantle provides larger viscous resisting force to balance the negative buoyancy associated with slabs and causes less deformation on the surface, consequently, smaller resisting shear stress on fault plane is required in order to match observed trench depths. Our viscosity structure with high viscosities for the lower mantle and transition zone is basically the same as Hager's [1990]; this viscosity structure suggests a resisting shear stress of about $15-30 \mathrm{MPa}$ on convergent plate boundaries, which is smaller than the $100 \mathrm{MPa}$ of Davies
[1980], but is in general consistent with the 14-40 MPa inferred from frictional heating models of subduction zones [Tichelaar and Ruff, 1993].

\section{Conclusions}

We have developed a finite element method with constrained elements and Lagrange multipliers to study tectonic faults in a viscous medium. With this method, a fault which represents the interface between an overriding and a subducting plate has been incorporated into a viscous flow model of subduction zones. Surface dynamic topography from the model with typical subduction zone parameters is characterized by a narrow and deep trench and a broadly depressed back arc basin. This suggests that trenches and back arc basins may originate from the compensation of subducting slabs.

Our models indicate that trench depth in general increases with fault dip, slab dip, slab length, and age of lithosphere prior to subduction. However, the fault dip angle and the age of lithosphere are more important in controlling trench depth than the slab dip angle. The length of thermal slabs does not greatly effect trench depth, as long as they are long enough to experience the phase change from olivine to spinel at $410 \mathrm{~km}$ depth. These trench depth to subduction zone parameter relations explain well the statistics of observed trench depths [Jarrard, 1986]. Observed trench depths of subduction zones with oceanic lithosphere on both sides of trenches have been corrected for fault dip angles, slab dip angles, and length of Benioff zone, based on the relationships from our models. Trench depth corrected only for fault dip and slab dip displays a clear correlation with age of lithosphere prior to subduction with a slope of $32 \mathrm{~m} \mathrm{~m} . \mathrm{y}^{-1}\left(27 \mathrm{~m} \mathrm{~m} . \mathrm{y}^{-1}\right.$ when elasticity is considered), which is consistent with that predicted by our models and is close to the seafloor subsidence rate of $36 \mathrm{~m}$ m.y..$^{-1}$. Further correction of trench depth for length of Benioff zones not only degrades the correlation between trench depth and age but also gives rise to much smaller slope than predicted by our models; this suggests that the length of Benioff zones used for the correction does not represent well the length of the thermal signal of slabs. Comparison between the trench depths corrected for dip angles of faults and slabs and those from models with different shear stresses on faults suggests that shear stress on faults in subduction zones may range from $15 \mathrm{MPa}$ to $30 \mathrm{MPa}$, depending on model details.

Acknowledgments. We thank L. Ruff and G. Houseman for constructive discussions and M. Parmentier, S. Willelt, and the Associate Editor for their reviews. This work was funded by the David and Lucile Packard Foundation and NSF grant EAR-8957164. Contribution number 5414, Division of Geological and Planetary Sciences, California Institute of Technology, Pasadena, California.

\section{References}

Barr, T. D., and G. A. Houseman, Distribution of deformation around a fault in a non-linear ductile medium, Geophys. Res. Lett., 19, 1145 1148, 1992.

Cazenave, A., A. Souriau, and K. Dominh, Global coupling of the earth surface topography with hotspots, geoid and mantle heterogeneity, Nature, 340, 54, 1989.

Christensen, U. R., Convection in a variable-viscosity fluid: Newtonian versus power-law rheology, Earth Planet. Sci. Lett., 64, 153-162, 1983. 
Cook, R. D., Concepts and Application of Finite Element Analysis, 2nd ed., 537 pp., John Wiley, New York, 1981.

Creager, K. C., and T. H. Jordan, Slab penetration into the lower mantle, J. Geophys. Res., 89,3031 - 3049, 1984.

Davies, G. F., Regional compensation of subducted lithosphere: Effects on geoid, gravity and topography from a preliminary model, Earth Planet. Sci. Lett., 54, 431-441, 1981.

Davies, G. F., Mechanics of subducted lithosphere, J. Geophys. Res., $85,6304-6318,1980$.

Davies, G. F., and F. Pribac, Mesozoic seafloor subsidence and the Darwin rise, past and present, in The Mesozoic Pacific: Geology, Tectonics, and Volcanism, Geophys. Mono., Ser., vol. 77, edited by S. Pringle, W. V. Sliter, and S. Stern, pp 39-52, AGU, Washington, D. C. 1993.

De Bremaecker, J.-C., Is the oceanic lithosphere elastic or viscous?, J. Geophys. Res., 82, 2001-2004, 1977.

Grellet, C., and J. Dubois, The depth of trenches as a function of the subduction rate and age of lithosphere, Tectonophysics, 82, 45-56, 1982.

Gurnis, M., Depressed continental hypsometry behind oceanic trenches: A clue to subduction controls on sea-level change, Geology, 21, 29. 32, 1993.

Hager, B. H., The viscosity profile of the mantle: A comparison of models on postglacial and convection time scales (abstract), Eos Trans. AGU, 7I(43), Fall Meeting suppl., 1567, 1990.

Hager, B. H., and R. J. O'Connell, A simple global model of plate dynamics and mantle convection, J. Geophys. Res., 86, 4843-4867, 1981.

Hager, B. H., and R. J. O'Connell, Subduction zone dip angles and flow driven by plate motion, Tectonophysics, 50, 111-133, 1978.

Hager, B. H., R. W. Clayton, M. A. Richards, R. P. Comer, and A. M. Dziewonski, Lower mantle heterogeneity, dynamic topography and the geoid, Nature, 313, 541, 1985.

Hetenyi, M., Beams on Elastic Foundation, 255 pp., University of Michigan Press, Ann Arbor, 1946.

Hilde, T. W. C., and S. Uyeda, Trench depth: Variation and significance, in Geodynamics of the Westem Pacific-Indonesian Region, Geodyn. Ser., vol. 11, edited by T. W. C. Hilde and S. Uyeda, pp. 75-89, AGU, Washington, D. C., 1983.

Hughes, T. J. R., The Finite Element Method. 631 pp., Prentice-Hall, Englewood Cliffs, N. J., 1987.

Jarrard, R. D., Relations among subduction parameters, Rev. Geophys., 24, 217-284, 1986.

Jungels, P. H., and G. A. Frazier, Finite element analysis of the residual displacements for an earthquake rupture: Source parameters for the San Fernando earthquake, J. Geophys. Res., 78, 5062-5083, 1973.

Kanamori, H., The state of stress in the Earth's lithosphere, in Physics of the Earth's Interior, edited by A. Dziewonski and E. Boschi, Amsterdam, North-Holland, pp. 531-554, 1980.

Karig, D. E., Origin and development of marginal basins in the western Pacific, J. Geophys. Res., 76, 2542-2561, 1971.

King, S. D., The interaction of subducting slabs and the 670 kilometer discontinuity, Ph. D. thesis, Cali. Inst. of Technol., Pasadena, 1991.

King, S. D., and B. H. Hager, The relationship between plate velocity and trench viscosity in Newtonian and power-law subduction calculations, Geophys. Res. Lett., 17, 2409-2412, 1990.

King, S. D., A. Raefsky, and B. H. Hager, ConMan: Vectorizing a finite element code for incompressible two-dimensional convection in the Earth's mantle, Phys. Earth Planet. Inter., 59, 195-207, 1990.

Lachenbruch, A. H., and J. H. Sass, The stress heat-flow paradox and thermal results from Cajon Pass, Geophys. Res. Lett., 15, 981-984, 1988.

Lyzenga, G. A., A. Raefsky, and S. G. Mulligan, Models of recurrent strike-slip earthquake cycles and the state of crustal stress, $J$. Geophys. Res., 96, 21,623-21,640, 1991.
McKenzie, D. P., Speculation on the consequences and causes of plate motions, Geophys. J. R. Astron. Soc., 18, 1-23, 1969.

Melosh, H. J., and A. Raefsky. The dynamical origin of subduction zone topography, Geophys. J. R. Astron. Soc., 60, 333-354, 1980.

Melosh, H. J., and A. Raefsky, A simple and efficient method for introducing faults into finite element computations, Bull. Seismol. Soc. Am, 71, 1391-1400, 1981.

Melosh, H. J., and C. A. Williams, Jr., Mechanics of graben formation in crustal rocks: a finite element analysis, J. Geophys. Res., 94, 13,96113,973, 1989.

Oxburgh, E. R., and E. M. Parmentier, Compositional and density stratification in oceanic lithosphere--Causes and consequences, $J$. Geol. Soc. London, 133, 343-355, 1977.

Park, C.-H., K. Tamaki, and K. Kobayashi, Age-depth correlation of the Philippine Sea back-arc basins and other marginal basins in the world, Tectonophysics, 181, 351-371, 1990.

Pribac, F. Superswells Due to Mantle Convection, Ph. D. thesis, 174 pp., Australia Nat. Univ., Canberra, A.C.T., 1991.

Richards, M. A., and B. H. Hager, Geoid anomalies in a dynamic Earth, J. Geophys. Res., 89, 5987-6002, 1984.

Ringwood, A. E., Composition and Petrology of the Eanth's Mantle, 618 pp., McGraw-Hill, New York, 1975.

Schubert, G., D. A. Yuen, and D. L. Turcotte, Role of phase transitions in a dynamic mantle, Geophys. J. R. Astron. Soc., 42, 705-735, 1975.

Sclater, J. G., Heat flow and elevation of the marginal basins of the western Pacific, J. Geophys. Res., 77, 5705-5719, 1972.

Sclater, J. G., D. Karig, L. A. Lawver, and K. Louden, Heat flow, depth, and crustal thickness of the marginal basins of the South Philippine Sea, J. Geophys. Res., 81, 309-318, 1976.

Sleep, N. H., Stress and flow beneath island arcs, Geophys. J. R. Astron. Soc., 42, 827-857, 1975.

Sung, C. M., and R. G. Burns, Kinetics of high pressure phase transformations: Implications to the evolution of the olivine - spinel transformation in the downgoing lithosphere and its consequences on the dynamics of the mantle, Tectonophysics, 31, 165-170, 1976.

Tichelaar, B. W., and L. J. Ruff, Depth of seismic coupling along subduction zones, J. Geophys. Res., 98, 2017-2037, 1993.

Turcotte, D., and G. Schubert, Geodynamics, 450 pp., John Wiley, New York, 1982.

Uyeda, S., and H. Kanamori, Back-arc opening and the mode of subduction, J. Geophys. Res., 84, 1049-1061, 1979.

Vassiliou, M. S., and B. H. Hager, Subduction zone earthquakes and stress in slabs, Pure Appl. Geophys., 128, 547-624, 1988.

Watts, A. B., and M. Talwani, Gravity anomalies seaward of deep-sea trenches and their tectonic implications, Geophys. J. R. Astron. Soc., $36,57-90,1974$.

Watts, A. B., J. H. Bodine, and N. M. Ribe, Observations of flexure and the geological evolution of the Pacific Ocean basin, Nature, 283, 532-537, 1980.

Zhao, D., K. Aki, and N. Biswas, How deep does slab penetrate beneath Alaska? (abstract), EOS Trans. AGU, 74 (16) Spring Meeting suppl., $312,1993$.

Zhong, S., and M. Gurnis, Viscous flow model of a subduction zone with a faulted lithosphere: long and short wavelength topography, gravity and geoid, Geophys. Res. Lett., 19, 1891-1894, 1992.

Zhong, S., M. Gurnis, and G. Hulbert, Accurate determination of surface normal stress in viscous flow from a consistent boundary flux method, Phys. Earth Planet. Inter., 78, 1-8, 1993.

M. Gurnis, Seismological Laboratory, California Institute of Technology, Pasadena, CA 91125.

S. Zhong, Department of Geological Sciences, University of Michigan, Ann Arbor, MI 48109-1063.

(Received June 14, 1993; revised March 10, 1994; accepted March 21, 1994.) 